\title{
Los géneros didácticos en la literatura jesuítica rioplatense
}

Didactical genres in the Jesuit literature in the La Plata-region

A la memoria de Walter Rela (1922- 2016)

Franz Obermeier*

Resumen: La mayoría de los estudios sobre la literatura jesuita en la región del Plata hasta ahora se centraron en un número muy pequeño de textos considerados los más importantes, como por ejemplo Ruiz de Montoya y Pablo Restivo, o la traducción de Nieremberg en Guaraní. En nuestra contribución, trataremos de tener en cuenta los textos menos conocidos y su uso didáctico. Después de establecer la tradición del diálogo didáctico en la historia de la literatura, mostraremos que los textos como Sermones y Explicación de Yapuguay, y algunos manuscritos devocionales no publicados, estaban estrechamente relacionados con el uso en las cofradías de trabajo social y educación religiosa entre los guaraní.

Algunos de estos textos obviamente tienen una doble función: fueron utilizados para la devoción personal de los guaranís o para oraciones conjuntas en reuniones de cofradías, pero al mismo tiempo ayudaron a los mismos jesuitas a mejorar sus conocimientos, proporcionando textos en una versión actualizada de guaraní como el hablado en las reducciones.

Palabras clave: Paraguay; Misiones jesuíticas; Literatura didáctica; Manuscritos devotos; Congregaciones Guaraníes Jesuitas; Aprendizaje de idiomas

Abstract: Most studies about the Jesuit literature in the La Plata region up to now focused on a very small number of texts considered the most important ones, as for instance Ruiz de Montoya and Pablo Restivo, or the translation of Nieremberg in Guarani. In our contribution, we will try to take into account lesser-known texts and their didactical use.

* Universitätsbibliothek Kiel, Alemania. E-mail: obermeier@ub.uni-kiel.de

80 Franz Obermeier. Los géneros didácticos en la literatura jesuítica rioplatense.... 80-103. 
After establishing the tradition of the didactical dialogue in literature history we will show that texts as the Sermones and Explicación by Yapuguay and some unpublished devotional manuscripts were closely linked to the use in the cofradías in charge of social work and religious education among the Guarani-indians.

Some of these texts obviously have a double function: they were used for the Guaranis' personal devotion or joint prayers in cofradias' meetings but at the same time helped the Jesuits themselves to improve their knowledge providing texts in an actualized version of Guarani as the one spoken in the reducciones.

Keywords: Paraguay; Jesuit missions; didactical literature; devotional manuscripts; congregations Guarani Jesuits; Language learning

Recibido: 5 de noviembre de 2017.

Evaluado: 21 de diciembre de 2017. 
En esta contribución vamos a analizar la literatura rioplatense en la época jesuítica desde un ángulo especial, poniendo en el centro el aspecto didáctico de algunos textos que nos parece que hasta hoy no han sido suficientemente valorizados. Nos concentraremos en libros para cofradías y para el aprendizaje del guaraní redactados por los jesuitas en las reducciones del Paraguay.

Parece evidente que hay ciertos géneros que se dirigen principalmente a la didáctica, como lo son los textos de catecismo o afines como los de devoción. Pero consideramos aquí la didáctica también en un sentido más vasto como formación no solo de los alumnos, sino también de los que hoy se llamarían los mediadores, principalmente los jesuitas, y también indígenas que podían, dentro de ciertos límites y con el consenso de los jesuitas, asumir tareas de formación religiosa, como por ejemplo en el ámbito de las cofradías; o escribir libros, como el célebre Nicolás Yapuguay. Hasta hoy no han sido muy investigadas esas congregaciones que existían tanto en las reducciones como en el contexto cultural de las ciudades coloniales.

En el estado actual de la investigación podemos apenas mostrar algunas líneas futuras para resaltar ciertos aspectos descuidados. Vamos a ver que el aspecto didáctico influye también en la microestructura de ciertos textos, y por eso tomamos ejemplos de un elemento como el diálogo a modo de estructuración de ciertos géneros. La definición de géneros tiene que ser relacionada también con aspectos no puramente textuales como lo son la iconografia ${ }^{1}$ y la performatividad en algunos como el teatro y la prédica. ${ }^{2}$ Hay, sin embargo, otros elementos a considerar. Podemos dar por ejemplo una definición de géneros privilegiando el aspecto del destinatario: ¿se trata de textos dirigidos a los mediadores jesuitas o de textos con aplicación concreta en un momento de performatividad en común como lo es el teatro? Pueden existir también estructuras adecuados para ambas aplicaciones.

Partiendo de una definición extensa vemos que la noción de género que parece pertenecer más a una definición abstracta de la historiografia de la literatura puede enriquecer nuestra visión de la literatura jesuítica y situarla en su contexto histórico.

La cuestión del público es central para entender la literatura didáctica. Muchas formas de géneros didácticos son bastante nuevas. En el sector religioso el catecismo es el más conocido en forma dialogada. El término de "catecismo" aparece por primera vez en el libro del obispo portugués Diogo Ortiz de Villegas (Calzadilla, c.1454-Almeirim, 1519) que tomó "catecismo" como préstamo del latín en el título de su obra: Cathecismo Pequeño (1504). Los catecismos más comunes del siglo son los de Petrus Canisius en varias formas (Maior, 1555; Minor, 1558; Minimus, 1556) y los de Roberto Bellarmino que también escribió dos variantes (Maior, 1598 y Minor, 1597). En el campo espiritual el género del catecismo ya tiene en su estructura característica de diálogo de Padre a catecúmeno, una estructura básicamente pedagógica. La función central del catecismo es transmitir conocimientos básicos sobre la religión a los creyentes. Pero el género es solo un elemento del discurso y este es muy limitado a unas fórmulas y a explicaciones. La misma estilización vale para el discurso en el teatro. El teatro moderno

\footnotetext{
${ }^{1}$ No podemos tratar aquí este importante aspecto como lo merece. Referimos el lector a nuestro análisis de los grabados en el "primer libro" de la imprenta jesuítica (de hecho, es el primer libro mayor) la Diferencia entre lo temporal y eterno de Juan Nieremberg, traducido por el jesuita José Serrano en guaraní (Obermeier, 2006).

${ }^{2}$ Sobre la performance Aguerre, 2015.
} 
nació (a pesar de textos precursores en la Edad Media) solo al umbral de la Edad Moderna poco antes de la Reforma en que tomó su mayor alcance.

Nuestro análisis es también importante para entender el contexto de un manuscrito rioplatense que intentamos editar según una copia encontrada en Filadelfia. La copia del ms. Gülich lleva un título que contiene información acerca de cuándo, por quién y por encargo de quién fue hecha.

"Abschrift / eines / Im Privatbesitz des Herrn von Gülich befindlichen / Handschriftlichen/ Guaraní = Fragmentes / Im Auftrage von / Julius Platzmann / für Herrn Dr. Karl Henning / angefertigt durch / Emanuel Forchhammer / Leipzig, im März 1878“،.

\section{La pedagogía jesuítica y una "enciclopedia de lo cotidiano"}

A pesar de la importancia del tema hay pocos trabajos que se ocupen de la pedagogía jesuítica y sus libros en la primera época colonial rioplatense. Los estudios de literatura muchas veces eligen como tema géneros y obras de mayor importancia o de autores conocidos, como el teatro de Anchieta (ver edición de 1977), y evitan temas difíciles como retórica o estudios generales de géneros. El teatro jesuítico encontró gran interés de los estudiosos. En civilizaciones avanzadas como la sociedad del México colonial tenemos una buena documentación acerca de cómo funcionaron esos textos y también tenemos documentos acerca de cómo fueron las representaciones. Hay muchos estudios sobre el teatro jesuítico de José de Anchieta en Brasil. El teatro se presta también para nuevas perspectivas teóricas. La tesis de Lima Ribeira Sales (2011) toma como ejemplo el Auto de São Lourenço de Anchieta, puesto en escena en la aldea de los Temiminó (Niterói) en 1587 para intentar encontrar indicios en el uso del cuerpo y la oralidad. Nuevos estudios consideraran el uso del teatro en el Brasil como formando parte de un ámbito performativo de trabajo misionero en que se incluyen imágenes (un ejemplo importante sería la obra de Nadal, 1593), libro muy leído en los ámbitos jesuíti$\cos$ ), teatro y sermones como un conjunto de medios para asegurar el éxito del trabajo misionero en las condiciones difíciles de la misión americana (Torres, 2006). Los géneros se influencian recíprocamente. Torres afirma que los jesuitas crearon un "catecúmeno-ator-orador-cristão indio" (2006, p.180).

El teatro no es siempre un género didáctico, pero lo era en gran parte en los siglos XVI y XVII, sobre todo para el aprendizaje del latín, en el uso que los jesuitas hicieron del teatro escolar en sus colegios europeos. Como ese sub-género de teatro didáctico moral y religioso desapareció completamente, solo un análisis retrospectivo puede intentar resaltar ese aspecto.

\section{El teatro}

Sabemos el papel que tenía en la pedagogía jesuítica el teatro, pero tenemos pocos documentos sobre la zona rioplatense. ${ }^{3}$ El teatro podía, dentro de la gran tradición de los autos sacramentales, personalizando la conditio humana en papeles alegóricos, poner en escena la suerte moral del hombre y de su alma en general. Es claro que se

\footnotetext{
${ }^{3}$ Ver Pla, 1967 y Rela 1990, con la transcripción del único texto conservado oralmente del teatro jesuítico, el Auto de Adan, pp. 172-175 que Manuel Gondra (1871-1927) fue el primero en transcribir (1990).
}

83 Franz Obermeier. Los géneros didácticos en la literatura jesuítica rioplatense.... 80-103. 
trata de un teatro didáctico escolar escrito según un modelo europeo y en una mixtura de lengua indígena-español y latín para los catecúmenos en Latinoamérica. Los temas de las piezas tenían un intrínseco carácter didáctico-religioso en la mayoría de los casos. En el Paraguay hay evidencias de la existencia de un tal teatro, se habla también de comedias escritas por jesuitas, pero carecemos de textos, si se descuenta un Auto de Adán transmitido oralmente hasta un siglo después de la expulsión de los jesuitas. Hay además una mención de una pieza con temática actual, en una Memoria en guaraní que habla de la producción de unas escenas de historia reciente sobre la conquista española de Colonia del Sacramento en 1704/1705, con la ayuda de una milicia de indígenas guaraníes. Esa Memoria (el título del manuscrito, "Diario de la conquista", es posterior, y el texto en su forma conservada fue escrito con alguna distancia temporal) menciona que una tal pieza fue mostrada delante del Sargento mayor Baltasar García Ros, más tarde gobernador del Paraguay, en una visita a la reducción Corpus en $1705^{4}$. La documentación sobre el teatro rioplatense colonial no es comparable con el rico saber que tenemos del Brasil o de México, mas sabemos por las pocas menciones en las fuentes que tuvo bastante propagación. El carácter de diálogos sobre la vida cotidiana del público era otro en el ms. Gülich y de cierto no era un texto con carácter escenográfico. El género se inscribe en una tradición de diálogo didáctico para transmisión de saber que tenemos que bosquejar en breve.

\section{El diálogo como género didáctico plurifuncional}

Tenemos que analizar antes de proceder al ms. Gülich las funcionalidades del diálogo en la historia literaria y didáctica. La didáctica dialógica está en el centro de la didáctica en la antigüedad. Abundan poemas de instrucción (Parménides) y diálogos instructivos. Con su alta tradición de poesía didáctica, ese género es profundamente influenciado por la voluntad de transmitir saber. En el caso de Platón, la forma del diálogo sirve no tanto para presentar resultados definitivos de una investigación filosófica, pero temas a discutir en su Academia. Se trata de exponer modelos para iniciar una discusión sobre un tema. Son justamente las aporías de la discusión las que la mantienen viva y causan nuevas perspectivas y preguntas para ulteriores encuentros. Es la tarea de la forma dialógica y el papel de Sócrates de provocar al alumno u otro filósofo con su mayéutica a proseguir la discusión, quebrando opiniones implícitas que se tenían por ciertas, pero se revelan infundadas o erradas. Para eso algunas veces pequeños elementos del mito o de cuentos son integrados como ejemplos que simbolizan los temas propuestos. Encontramos esa mezcla de microgéneros en muchas formas todavía en épocas posteriores.

La literatura medieval conocía poco de Platón (solo el Timaios/Timeo en traducción latina por su parte matemática). El modelo del dialogo didáctico era De oratore de Cicerón, u otros textos como los diálogos con figuras alegóricas en Boecio (Consolatio Philosophiae, c.525) (1981) o los soliloquios de Petrarca (De secreto conflictu curarum mearum, 1347-1353) y sus diálogos entre figuras alegóricas De remediis utriusque fortunae (escrito entre 1354 y 1367), uno de los libros más leídos en el Renacimiento. La retórica tradicional tuvo siempre un componente pragmático y dialógico. La ars aren-

\footnotetext{
4 Ver nuestra edición de un manuscrito en guaraní sobre esa guerra (Thun et. al. 2015). En el original al fin del texto: 1.c., p. 149/150 en nuestra traducción: "Entonces los de Corpus representaron [teatralmente] los hechos pasados ante el Gobernador"
} 
gandi del siglo XIII se apropia una función declaradamente comunicativa (Moos, 1993). Libros como la Consolatio de Boecio alcanzan una recepción mayor en la Edad Medieval e iniciaron todo un género de literatura consolatoria en forma dialógica.

La transferencia de conocimiento a través del diálogo se hizo tradicional en la Edad Medieval. La forma dialogada se utiliza mucho desde la Edad Media para exponer conocimientos básicos en un campo, sea este la doctrina cristiana o cualquier otra rama del saber.

La Gramática de Aelius Donato (siglo IV) está escrita de esta forma (Hartmann, 2007). El texto más conocido de un supuesto diálogo era probablemente de Honorius Augustodunensis, benedictino, tal vez de origen irlandés (c.1080-1150/51) que escribió en Canterbury en torno al 1100 el Elucidarium, libro básico utilizado en la pedagogía de la época y que fue traducido a todas las lenguas europeas. El libro expone una concepción teológica, mas presenta una teología para uso en la vida cotidiana y se dirige a clérigos y laicos, por lo cual alcanzó un éxito mayor.

Los diálogos utilizados para la práctica de idiomas extranjeros son también un tipo textual muy antiguo. Son normalmente pequeñas conversaciones sobre temas de la vida cotidiana, en los que se introducen conocimientos para interacciones como saludar, rogar, agradecer, entre otros. Muy temprano los libros de aprendizaje de lenguas vernaculas también usan diálogos con temática práctica, por ejemplo del área del comercio como vemos en ejemplos ingleses hechos para aprendizaje del francés en el área de Flandres, importante para el comercio de tejidos. Algunos de eses libros contienen modelos coloquiales de compra y venta de mercancías. Bastante temprano esos libros fueron también impresos. ${ }^{5}$ Hay un uso análogo del coloquio en libros o capítulos para aprendizaje de lenguas indígenas en el siglo XVI. En el libro del viajante francés Jean de Léry (1578), en el capítulo XX se encuentra también un coloquio con situaciones modelo (salutación, trueque, preguntas básicas sobre la civilización europea) en lengua tupi que Léry ciertamente no ha escrito él mismo, pero que le fue dado por un truchement (intérprete), del grupo de célebres marineros go-between que vivían durante años entre los indígenas y sabían mejor la lengua que Léry con una breve estadía de dos años. 6

También en la España humanista los diálogos tienen una gran tradición, que aquí no podemos mencionar sino brevemente. ${ }^{7}$ Todavía no hay una historia de la teoría del diálogo, pero la investigación está iniciando. 8

\footnotetext{
5 Becker, 2003, especialmente pp. 70-79, análise de dialogos de venta de mercancias en eses libros: 1.c., pp. 276-340. Hüllen, 2006, pp. 78-139. Un de los primeros impresos en Inglaterra de ese tipo de libro fue del célebre editor William Caxton (1483). Ese libro fue adaptado de un "Le livre des mestiers" que consiste de dialogos franceses-flamencos, redactados en el siglo XIV por un maestro de escuela de la ciudad de Brujas (Brugge). Caxton havia vivido en Brujas antes de aprender el oficio de impresor en Colonia. Después volvió a Inglaterra y fue un de los impresores más importantes de esa época.

6 Léry escribe: “[...le] colloque suyvant, qui fut fait au temps que i'estois en l'Amerique, à l'aide d'un truchement" (Léry, Histoire, reedición de Ginebra: Chuppin 1580, p. 306). En realidad, Léry tenía cierto saber básico del tupi, como sabemos por palabras y expresiones en el resto de su libro, pero ha escrito de ese capítulo sólo una lista de aldeas indígenas al final. Sobre ese coloquio ver también Foltys, 1992. 7

7 De la extensa literatura citamos: Batllori 1990, Hempfer, 2004. Briesemeister, 2004.

8 Sobre la teoría del diálogo con énfasis en la literatura alemana ver Kilian, 2002 y 2005. Sobre la tradición española: Gómez, 1988 (con un "Catálogo bibliográfico", pp. 217-230 y 1990).
} 
El libro con un texto dialogado con más éxito en el inicio de la Edad Moderna temprana fue tal vez el de Sebastián Castellio (1542-1543-1545), cuyo uso dominará el aprendizaje del latín por siglos. El autor Sebastián Castellio (Sébastien Châtillon) (St. Martin-du-Fresn, Saboya, 1515-Basilea, 1563) era escritor protestante y crítico de Calvino. De modelo sirvieron claramente los Colloquia familiaria de Erasmus (Basilea: Frobenius 1518).

El diálogo tiene que ser visto en relación con la formación retórica de los autores y una gran tradición de oratoria sagrada. Está claro que después del Concilio de Trento la Iglesia dejó una anatemización de una elocuencia sagrada. Pawling (2004, p. 101) lo formula bien: "Los teólogos del Concilio admitieron la legitimidad de un arte oratorio cristiano". El aspecto práctico del Concilio de Trento era la creación de textos oficiales de uso obligatorio no conocidos anteriormente: el catecismo para párrocos (1566), el breviario (1568), el misal (1570), el martirologio (1583), el pontifical (1596), el ceremonial de los obispos (1600) y el ritual (1614) (Stefano/Zanatta, 2009). Los jesuitas respondieron a ese pedido del Concilio de Trento (Pawling, 2004, pp. 106-125). A pesar de tener una retórica ecléctica, tenían teóricos importantes y crearon una Ratio Studiorum con el uso de varios géneros apropiados para la educación. Iniciaran temprano, ya en torno a 1557, el teatro escolar en que representaron piezas en latín, diálogos alegóricos y comedias de tema bíblico en la apertura de cursos, los temas solemnes en latín, mas también con entretenimientos intercalados en lenguas vulgares como el castellano (Verdu, 1973, p. 60; Pawling, 2004, p. 106). Ese bilingüismo funcional se hizo característico, también en obras latinoamericanas como el mencionado Auto de Adán en que se muestra como trilingüismo latín/español/guaraní.

En la tradición de la literatura infanto-juvenil, el diálogo se mantuvo todavía hasta el siglo XX. Parecía una posibilidad fácil de instaurar el papel de un narradorinstructor en el texto y de justificar sus intervenciones explicativas en su discurso. Algunas veces es un método para tratar un tema de manera comprensible para los jóvenes. Los primeros libros narrativos del escritor brasileño infanto-juvenil Monteiro Lobato (1882-1948), todavía usan el diálogo con esa función. Su valor consiste en escribir en consideración del lector intencional, a diferencia de muchos libros de lectura para la escuela del siglo XIX que solo usan el diálogo como un cuadro para presentar textos demasiado complicados para los jóvenes. Su primer libro de éxito fue Aventuras de Hans Staden (1927), tomando como tema el cautiverio de un alemán que ha escrito el primer libro sobre el Brasil en 1557, después de su regreso a Alemania. ${ }^{9}$

\section{El manuscrito Gülich en el contexto de la didáctica jesuítica}

Hemos redescubierto la copia del manuscrito (que llamamos según el nombre original del propietario del siglo XIX "ms. Gülich", en lo que sigue, manuscrito G) en 2007 en la Biblioteca de la Universidad de Filadelfia; estaba mencionado en el catálogo de John Weeks de la colección Brinton (Weeks, 2002). Es una copia del siglo XIX. Has-

\footnotetext{
${ }^{9}$ Hans Staden: Warhaftige Historia. Zwei Reisen nach Brasilien, (1548-1555) / Historia de duas viagens ao Brasil. Kritische Ausgabe / edição crítica: Franz Obermeier. Übertragung ins heutige Deutsch: Joachim Tiemann. Tradução ao português: Guiomar Carvalho Franco. Revisão: Augusto Rodrigues 2007. Sobre el tema de la literatura infanto-juvenil: Obermeier, 2016a, pp. 153-155.
} 
ta ahora, nadie ha investigado el material. Para cuestiones de proveniencia referimos a otras publicaciones nuestras y la introducción a la edición crítica futura. ${ }^{10}$

La versión de Filadelfia es una copia hecha en el siglo XIX de un original hoy destruido, procedente de la colección del embajador alemán en la región, Friedrich von Gülich (Osnabrück, 1820-Wiesbaden, 1903) (Obermeier, 2016b). El descubrimiento de un segundo manuscrito con una versión extensa del texto en Luján (de aquí en más, manuscrito L) se debe a las investigaciones del grupo Langas en París, en el año 2015 (Adoue/Oratin/Boidin, 2015). Nombramos nuestra copia "ms. Gülich", la otra, "ms. de Luján”.

Nuestra edición en preparación del ms. Gülich (Thun, et. al., 2018) es la segunda de un texto mayor del "temporal" (secular) en guaraní de las reducciones, después de la edición de la memoria sobre la conquista de Colonia del Sacramento en 1704/1705, publicada como primer libro en el cuadro del Proyecto Peky (Thun, et. al., 2015). Como en esa edición vamos a dar una amplia introducción para contextualizar el manuscrito, podemos aquí dejar de lado las cuestiones sobre el contenido. La existencia de un texto sobre normas de comportamiento en las reducciones, puniciones e instrucción tiene que ser explicada, también en el cuadro de los otros manuscritos en guaraní que conservamos de la región. Hay varias cuestiones importantes en cuanto al contenido y a los destinatarios de tal texto, si eran indígenas o misioneros, o los dos. El cuadro de Diálogos entre un indígena y un jesuita sirve ciertamente a jóvenes misioneros para aprender a dominar un uso pragmático correcto, y con carácter de modelo en cuanto a la explicación verbal de esas normas en guaraní. Ciertamente es uno de los textos mayores de la época en la región, y merece particular atención. Vamos a esclarecer esas preguntas en la introducción de la edición y a determinar el lugar excepcional del ms. Gülich en un contexto mayor de manuscritos de las reducciones en los primeros decenios del siglo XVIII.

\section{Normas sociales de comportamiento en la literatura}

En el contexto del ms. Gülich no hay un aspecto filosófico, pero sí un carácter didáctico sobre normas de la vida cotidiana. El diálogo se basa en el saber cotidiano como recetas de cocina y tiene pragmática normativa. Estamos en una época en que libros normativos de alta calidad literaria encuentran sus lectores. Del Cortegiano de Baldassare Castiglione (escrito entre 1513 y 1524, publicado en forma definitiva en 1528) al Galateo de Giovanni Della Casa (1503-1556, publicación póstuma de 1558) el tratamiento literario de normas de comportamiento es típico para una época en que

\footnotetext{
${ }^{10}$ Obermeier, 2011 y 2015. Nuestra hipótesis es que los dos manuscritos conocidos son de la colección Pedro de Angelis (1784-1859) y que fueran vendidos por él en 1856. El catálogo de venta de la colección que llegó después al Brasil fue una de las primeras bibliografias importantes de la historia rioplatense. Se publicó como Pedro de Angelis, Colección de obras impresas y manuscritas que tratan principalmente del Río de la Plata, sin lugar, en 1853, ciertamente en pocos ejemplares. El texto de esa bibliografia está disponible en línea sin el Apéndice: http://www.cervantesvirtual.com. El Apéndice sobre la parte etnolingüística de esa colección se refiere a esa obra, pero de Angelis lo publicó con una tirada limitada y lo distribuyó a algunos amigos y a posibles compradores solo en Buenos Aires. Un manuscrito mencionado en un Apéndice al Catálogo de De Angelis como "Diálogos en lengua guaraní. Manuscrito en 12" es nuestro texto de diálogos. De Angelis probablemente vendió un ejemplar a su amigo Gülich. La otra copia de ese texto quedó en manos de de Angelis hasta 1856, según creemos, y se vendió a Rafael Trelles, después llegó a través de la colección Enrique Peña al Museo Udaondo de Luján. Hemos dado a luz una edición comentada del Apéndice: Obermeier 2017a.
} 
normas, antes reservadas a las clases altas, se imponían en un proceso histórico bastante lento pero continuo a la vida de otras capas de la sociedad. Esa literatura también estimula tempranamente una parodia satírica que en la literatura alemana encontramos por ejemplo en la obra del luterano Friedrich Dedekind (1524-1598). Su libro Grobianus (1549) ha dado el nombre de Grobianismus en alemán ("Grobian” es patán en alemán). Adaptado por Caspar Scheidt (1551) en una versión libre y extensa en versos en alemán el libro tuvo un gran éxito. El personaje del pícaro que le es muy vecino también inspiró versiones femeninas. Dedekind ya tenía un breve anejo con una mujer que carecía de nombre pero se comportaba de manera semejante al héroe masculino. Scheidt creó más tarde (1572) un complemento femenino del patán, que nombró de manera análoga la "Grobiana", que Dedekind hizo aparecer con el nombre Grobiana, que tomó de Scheidt a partir de una nueva edición de 1554, completando así su pareja de patanes en un "Grobianus et Grobiana".

El disciplinamiento era un lado imprescindible del adoctrinamiento religioso de los indígenas. El alma de los indígenas era como una tabula rasa para los misioneros; según la concepción aristotélica del saber tenían que internalizar las reglas como parte de su propio carácter. La literatura moderna sobre las reducciones apenas ha resaltado el aspecto de la rigurosa presión en la vida social o de las puniciones corporales en las reducciones (González, 1994), hecho que no cabe en la visión "edulcorada" de las reducciones, que con carácter apologético se propagó, sobre todo a partir de la célebre obra del polígrafo italiano Lodovico Antonio Muratori (1743) y en una corriente apologética de la historiografía hasta hoy. Tal vez esa visión era también una reacción publicística frente a la corriente de literatura antijesuítica de la época.

Sin poder entrar en los pormenores del ms. Gülich podemos ya constatar un hecho evidente. Sus diálogos son ante ese telón de fondo cultural un género plurifuncional. Sirven para establecer los comportamientos aceptables y las puniciones con dos funciones: al formularlas, afirman las normas para quienes no obedecen a esas reglas implícitas. Pero sirven también para una explicación adecuada de esas normas; para ello es el diálogo el microgénero apto, porque cada infracción de norma presupone una representación de esa norma a quien la transgredió. Eso no es tan fácil en una lengua que no se domina enteramente como lo era el guaraní para muchos misioneros. Un texto como el ms. Gülich sirve de ese modo también para enseñar a los jóvenes misioneros que no dominaban adecuadamente ese aspecto de la lengua, la pragmática de imponer esas normas en el diálogo cotidiano y conflictivo. El diálogo en el texto se vuelve bifocal: afirma la normativa y encuentra una forma lingüística a esa norma, usando la pragmática del diálogo para su transmisión. Ulteriores análisis tienen que mostrar si es verdaderamente una pragmática de lengua hablada, o si el diálogo es solo una forma abierta estilizada para exponer mejor esas normas, como lo es en muchos diálogos de ese tiempo escrito por autores no muy dotados. Pensamos que el aspecto de uso concreto es evidente y que por eso escribir un texto extenso como el ms. Gülich presupone para mayor éxito una integración de elementos de la lengua hablada. Eso sirve para fortalecer el carácter didáctico, y asegura el éxito de un uso real de elementos de esos diálogos modelo. El microanálisis futuro tiene que mostrar cómo el texto se intercala entre el uso del diálogo modelo y el lenguaje estilizado oral como reflejo de una diglosia entre lengua religiosa y lengua del temporal/secular en las reducciones jesuíticas al inicio del siglo XVIII, del cual hace parte el ms. Gülich.

No es extraño que tengamos dos ejemplares de tal texto: la versión abreviada del ms. Gülich era tal vez la copia privada para uso personal de un jesuita y así una versión 
“didáctica" para uso concreto. La versión extensa de Luján era tal vez una colección para varios usos. Esa elección de partes de un material amplio para una copia ocurre también en el célebre manuscrito del Pojha nana, texto farmacéutico en guaraní atribuido al Hermano Manuel Villodas de 1725, que se conserva en varias formas abreviadas. A pesar de su ordenamiento errático, podemos deducir por la numeración dada en los títulos de los capítulos, que se refieren a un texto mucho más extenso. ${ }^{11} \mathrm{La}$ versión entera no se conservó.

\section{Literatura didáctica interna para formación de los jesuitas}

Tenemos que contextualizar nuestras hipótesis sobre el ms. Gülich con una breve ojeada al uso didáctico que los jesuitas hicieran de otros géneros de forma análoga.

Esa función no es única y se constata en otros textos semejantes. Un buen ejemplo que podía también reconocer al autor de los Diálogos, por lo menos en una versión anterior es un manual para fundar reducciones como género: las llamadas Advertencias del jesuita Anton Sepp (1655-1733).

Sabemos que la literatura para uso interno se inició ya muy temprano en la época colonial sobre todo con descripciones. La administración colonial del Consejo de las Indias de Sevilla tenía ya en el siglo XVI la intención de coleccionar saber sobre las colonias en descripciones estandarizadas. La confrontación con la naturaleza de las colonias está en el origen de todo un género descriptivo que también forma parte de los primeros textos de la "literatura" de los países en cuestión. En el Brasil también muchos textos de la primera literatura sobre el país son Tratados, vale decir en ese caso descripciones del país que resaltan su riqueza y su valor único para la corona portuguesa o más tarde española que en ese tiempo reinaba sobre Portugal y sus colonias (Magalhães de Gândavo, 1576; Soarez de Sousa, 1587, Cardim, 1997). En la obra Diálogos das grandezas do Brasil escrita entorno de 1618 por un colono que hoy podemos identificar con el cristiano nuevo Ambrósio Fernandes Brandão (1555-1618) tenemos el primer caso de una literalización del saber factual a través de un texto dialogado que echa también luz sobre el carácter de los diálogos contemporáneos en guaraní.

El ejemplo que tomamos es del siglo XVIII, de un autor conocido por sus relatos de la vida en las reducciones, el jesuita tirolés Anton Sepp. Sus Advertencias son conservados en un manuscrito que lleva el título: Algunas advertencias tocantes al gobierno temporal de los pueblos en sus fábricas, sementeras, estancias y otras faenas. Es datado: "Fecha en el pueblo de S. Joseph, día de S. Antonio de Padua, a 13 de Junio de 1732" y da el nombre del autor Sepp (Sepp, 1958). A pesar de su carácter tardío es para nosotros un modelo a comparar temática y estructuralmente con el ms. Gülich. El género de manuales sobre cómo fundar nuevas reducciones no está bien documentado, porque se trataba de textos que por su carácter práctico no se conservaron. El ms. Sepp es uno de los ejemplos en forma muy abreviada que tal vez fuera hecho a pedido del provincial y que por eso se conservó. El público son los jesuitas, pero también los indígenas de la élite de mayordomos u otros que les ayudaron. Se trataría del mismo carácter bifocal que tiene el ms. Gülich. Sepp era un experto porque ya había fundado reducciones en época anterior. Su texto se limita a algunos temas importantes para que la nueva

\footnotetext{
${ }^{11}$ Sobre esos manuscritos ver Melgarejo, 2014 y sobre una nueva versión abreviada descubierta en el IAI: Obermeier, 2017b.
} 
colonia pueda sobrevivir. Pensamos que en 1732 Sepp copia (de memoria o de un modelo escrito que tenía al alcance de sus manos) viejos textos de una época en que la fundación de nuevas reducciones era más frecuente que en 1732. Presentamos el esquema de los capítulos del contenido.

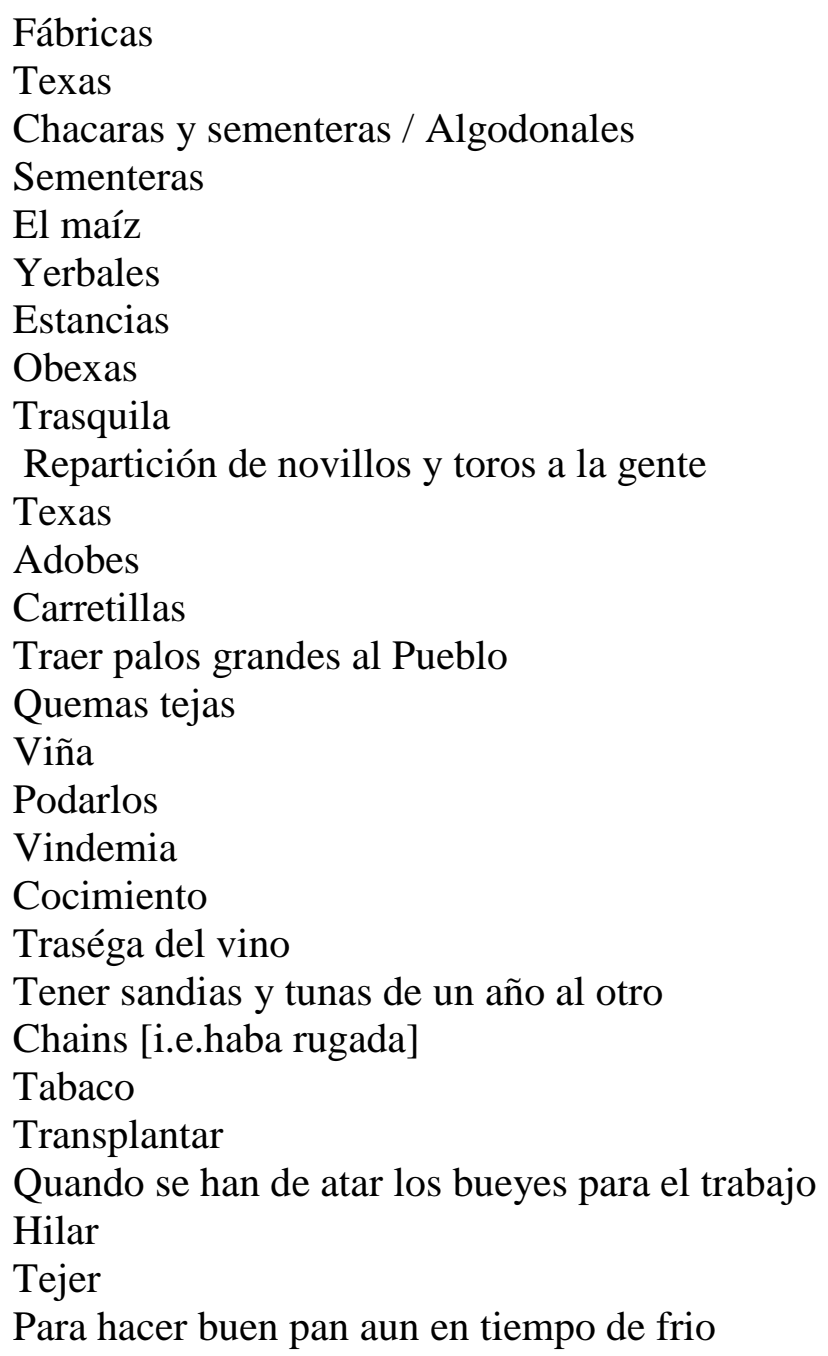

Se ve que algunos temas coinciden con los temas del ms. Gülich. Aquí la didáctica se vuelve modelo de cómo comportarse en la fundación de una nueva colonia, y en la vida cotidiana, ejemplo que conocemos también de otras tradiciones literarias como del libro de viaje del capuchino francés Yves d'Evreux, Suitte de l'histoire en el norte del Brasil (París 1615, no circuló, ed. 2014) que contiene capítulos con consejos a los nuevos colonizadores de São Luis do Maranhão. 12 Tenemos que ver si podemos constatar eses aspectos didácticos para mediadores también en otros tipos de textos.

\footnotetext{
${ }^{12}$ Ver en nuestra edición crítica Yves d'Évreux, 2014 el Cap. XLIX: "Instruction pour ceux qui nouuellement vont aux Indes", pp. 250-254.
}

90 Franz Obermeier. Los géneros didácticos en la literatura jesuítica rioplatense.... 80-103. 


\section{Sermones y sermones modelos}

Hay en toda literatura varios géneros que se pueden imaginar como círculos concéntricos de textos más o menos fijos con elementos en solapamiento: al centro de cada literatura religiosa hay algunas oraciones que no cambian. Claro que en el caso de los textos centrales no había necesidad de adaptaciones. Los textos eran aceptados después de mucha polémica con el obispo Cárdenas sobre el uso de traducciones correctas en guaraní. Ese conflicto había tenido lugar generaciones antes, más en su alcance polémico internacional estaba ciertamente todavía presente en la conciencia de los jesuitas de la generación de 1700. En el caso de los catecismos tampoco hay problemas, son modelados en base a textos europeos aceptados y lo que es libre es la parte explicativa y algunos otros "paratextos". El uso educativo implica aquí en gran parte un lenguaje simple y la situación dialógica es más o menos el juego de preguntas y respuestas fijas y carece de contextualización pragmática.

En cierto momento, cuando el conocimiento de la lengua indígena aumentó entre los misioneros y sabían más de su uso concreto, esos textos básicos parecieron no ser ya suficientes para la formación religiosa según el nivel alcanzado.

En ese momento que nos parece ser logrado en las reducciones al inicio del siglo XVIII es lógico que se necesite otro material. Hay otros textos que ponen el acento en el aspecto explicativo, como algunos manuscritos del decenio de 1710-1720 sobre Educación religiosa que vamos a tratar en estudios ulteriores. Lo mismo vale para los textos más conocidos de la imprenta jesuítica del decenio 1720-1730. Tenemos en los dos célebres libros del indio Yapuguy (1724 y 1727) no solo un catecismo, más lo que se publica en la imprenta jesuítica va a ser una Explicación del Catecismo por Yapuguay (1724 y 1727). Es también entendible que no tengamos un libro de sermones de Yapuguay, sino un libro de Sermones y exemplos (ese último micro-género de ejemplos era todavía más libre y podía ser usado en cualquier contexto y no tenía tan alta "autoridad religiosa", más bien una temática moral general con tenor religioso) en otro escrito bajo la dirección de un jesuita. La Explicacion contiene además un sermón modelo. ${ }^{13}$

A pesar de toda la gran tradición de oratoria latina y española, los sermones no tenían una normativa absoluta aceptada y eran un género bastante libre. Pero la temática era confinada a explicación de textos religiosos, y solo se admitieron ejemplos de la vida social de creyentes como los hay en textos históricos como el de Ruiz de Montoya (1639). Él habla simple, se presta más para esos textos que para textos de pura doctrina: el personaje indígena entra en cuestión como personaje en búsqueda de una verdadera religión (además, eso acontece como parte de una situación de vida pragmática y realista en las reducciones) cuando se trata de explicar los textos doctrinales o los sermones inadecuados linguísticamente a los indígenas que querían entenderlos. En esos textos sobre todo en una versión impresa que implica otros niveles de control por superiores y otros padres "lenguas" o "lenguaraces"- será justamente el "branding" (crear una marca) de "Yapuguay" que garantiza su actualidad religiosa y lingüística, también si pensamos probable a la participación de otros indígenas en el proceso multiforme de la redacción de esos textos. Por lo demás, el "Yapuguay" ponía un personaje identitario para los guaraníes en el centro de su instrucción religiosa.

\footnotetext{
${ }^{13}$ Es de notar que esa parte falta en algunos de los ejemplares conservados. (Ejemplar de la Colección Mindlin hoy en la USP, São Paulo). Muestra que era tal vez inserto a pedido de algunos como también lo afirma el título del capítulo: [Pt. 2] "En gracia de algunos que la han pedido vá aquí toda la historia de la passion en forma de sermon. Passio Domini nostri Iesu Christi”.
} 
Hay otro aspecto importante que podríamos llamar el flujo del tiempo: ese método apropiado conscientemente de reescritura de los sermones de los jesuitas implica y reflexiona también sobre un aspecto temporal. Aspecto temporal de la parte de los jesuitas, que tenían que aceptar los límites de su dominio de la lengua aplicada a pesar de los muchos años que ya existían las reducciones, se hicieran conscientes de que el material lingüístico que habían aprendido con Ruiz de Montoya no era el más adecuado. Aceptaron que se necesitaba crear un nuevo lenguaje devocional más actual que la lengua de Ruiz de Montoya, que no se había impuesto en todos sus aspectos. Esa escritura era un work in progress, o todavía en muchos elementos un punto de partida más que un éxito. Y según nuestra hipótesis es el problema al cual respondían no solo los textos del Yapuguay, sino también los otros múltiples manuscritos que tenemos de los primeros decenios del siglo XVII y que reservamos para ulteriores estudios. Sería también una de las razones para el surgimiento de textos múltiples en forma manuscrita, en una fase en que se podía pensar que la imprenta trabajando desde el inicio del siglo XVIII y sus posibilidades, ya eran prometedores y podían ser ampliamente suficientes para propagar esos textos en medio de un público mayor de las reducciones.

Hace falta ver aún otro aspecto de esos textos didácticos: el público lector al que estaban destinados. Está claro que los sermones y explicaciones de Yapuguay tienen ese aspecto doble como lo tiene el ms. Gülich: pueden ser utilizados en situaciones reales (didácticas o devocionales), pero también para mejorar la capacidad lingüística del dominio de la lengua por los jesuitas mismos. Vemos el uso mayor de gran parte de ese tipo de texto representado en los del Yapuguay entre los indígenas en las cofradías, un aspecto muy descuidado de la investigación sobre las reducciones.

\section{Literatura para cofradías y devoción personal}

Es extraño que haya varios estudios actuales de cofradías en un ambiente urbano o de afroamericanos en las Colonias, pero casi nada sobre las cofradías en las reducciones. ${ }^{14}$ Sabemos que había Cofradías en todas las zonas de América Latina muy temprano, también en zonas apartadas como la Chiquitania (Fischer, 1989, p. 94). Las que eran para personas de origen indígena se llamaban cofradías de naturales en la terminología de la época.

Cofradías son un cierto grupo de personas que se juntan para realizar sus prácticas religiosas regularmente y se dedican a una devoción especial, sea a ciertos santos como San Miguel, o a la ayuda a los grupos de los miembros o a otra gente desfavorecida. Eran, por así decir, también grupos participativos que facilitaron a ciertos grupos descuidados o en situaciones difíciles (enfermos, redención de cautivos, como por ejemplo en Europa los cristianos cautivos de musulmanes) o socialmente de poca integración en estructuras de poder (mujeres), una vida cultural propia en un contexto religioso social. Está claro que necesitaban también textos propios o modelos como ciertamente lo podían ser los libros de Yapuguay. La imprenta jesuítica hacía posible una mayor propagación de esos textos en número y así los prefectos de congregaciones $\mathrm{u}$ otros mayordomos miembros que sabían leer y escribir tenían a mano un ejemplar para ayudar a la formación religiosa de sus miembros en las reducciones que no podía hacer-

\footnotetext{
${ }^{14}$ Introducción general al tema: Takeda, 2017. Estudios especiales y locales: Fogelman, 2000 y 2006, Luca, 2010, Cirio, 2000, Rosal, 2006 y 2007, Sánchez, 2006, Peña, 1994, Cruz, 2002 y 2007. Sobre los negros en la zona rioplatense y sus cofradías ver también Borucki, 2015.
}

92 Franz Obermeier. Los géneros didácticos en la literatura jesuítica rioplatense.... 80-103. 
se solo por dos jesuitas. Se sabe que en la mayoría de las reducciones había solo dos padres. 15

Las cofradías son un punto importante para una devoción que se sitúa entre una vertiente personal y oficial. El jesuita brasileño Serafim Leite lista todas las cofradías que existían en el Brasil entre los jesuitas y sus alumnos del siglo XVI y XVII. ${ }^{16}$ El Papa Gregorio XIII permitió que se erigiesen en 1579 doce Cofradías en el Colegio romano (Leite, 1938, II, p. 324). Algunas en el Brasil recibieron muy temprano su patente, como por ejemplo la Cofradía mariana de Bahía de 1586, inaugurada en 1588. La mayoría estaba ligada a reliquias (cabezas de Santa Úrsula y compañeras de las cuales 6 reliquias estaban repartidas en el Brasil ya en el siglo XVI). Algunas eran para grupos especiales como la de Oficiais Mecânicos, 1614 en Bahía y Pernambuco o la de los Reyes Magos del Colegio de Río 1586 para esclavos indios. Siguen tradiciones de los países de origen como en el caso del Brasil, los de Portugal, como la devoción a la Cruz, a la pasión, a patrones locales o al Nombre de Jesús, titular de la Compañía de Jesús. Las Marianas tenían varias denominaciones, por ejemplo la del Colegio Romano aquella de Virgen de la Anunciata. Todos permitían ciertas indulgencias y eran integradas en varios tipos de fiestas; además de las dedicadas a patronos había fiestas jubilares, rogativas, gratulatorias o de desagravio. Con iglesias especiales las cofradías tenían también una notable influencia en la arquitectura religiosa colonial, como se ve en iglesias especiales de pardos u otros grupos. 17

Sabemos que algunas cofradías que existían en las reducciones tenían significación concreta. Los hombres en edad de integrar las milicias pertenecían a la cofradía del Arcángel San Miguel (Avellaneda, 2003). San Miguel tiene también alta presencia en la iconografía de las Doctrinas (Affani, 1999/2008). Como príncipe de las milicias para derrotar al mal (ver la imagología en Ruiz de Montoya, 1639) se hizo una figura emblemática que asumía el papel que tenían antes los hechiceros (“pagés” en guaraní) indígenas de decidir sobre el éxito de la guerra. Ecclesia militans y cultura nativa se encuentran así en un común denominador, en un tercer espacio para reaccionar a pedidos de la administración colonial, integrando tradiciones guerreras propias. Uno de los pocos documentos sobre los miembros de una congregación mariana en Corrientes de 1698 a 1714 muestra que la mayoría de los elegidos por los miembros eran soldados, los prefectos sargentos mayores, también en menor número capitanes. ${ }^{18}$ El rango militar no determinaba, sin embargo, la función en la congregación, donde había elecciones libres. En ese caso especial de Corrientes tenemos un ejemplo de que una congregación mariana es claramente para los militares. Los rangos cambiarían también de un año a otro.

\footnotetext{
${ }^{15}$ Ver sobre el tiraje y la repartición de los libros de la imprenta jesuítica argentina basado en los inventarios de las reducciones después del exilio (Obermeier, 2016c).

16

${ }^{6}$ Leite brinda el nombre de las corporaciones documentadas en el Brasil, su repartición geográfica y su fundación documentada. Las más frecuentes son las Marianas, las del SS. Sacramento y las de las almas del Purgatorio que había en todas las aldeas, en los colegios había normalmente las Marianas y las de Santa Úrsula y compañeras, y después otras especiales dedicadas a Santos o patronos locales (Leite, 1938, II, pp. 323-331).

${ }^{17}$ Ver sobre la historia de las congregaciones marianas Villaret, 1947. Sobre congregaciones en el Paraguay: Hernández, 1913, I, pp. 309-310; Leonhardt, 1931, Gilas/ Morales/ Martínez, 2014.

${ }^{18}$ Leonhardt, 1931, § IX, también referido en Villaret 1947, p.256.
} 
Las congregaciones presentaran a sus miembros indulgencias mayores. ${ }^{19}$ Había también congregaciones para mujeres, cofradías especiales existían para indígenas en el ámbito colonial. Esas últimas no eran necesarias en las reducciones, donde la población entera era de descendencia indígena, ese tipo es más importante cuando los descendientes indígenas estaban integrados en la sociedad colonial como en las ciudades coloniales del Brasil o de la región urbana rioplatense. Había también cofradías para grupos sociales y sobre todo profesiones. Vemos que las cofradías tenían en un ámbito religioso así también un aspecto participativo de gente normalmente excluida de estructuras de poder.

Sabemos que había una gran tradición oratoria en ocasiones de fiestas del colegio como la apertura solemne de un nuevo semestre. En esos casos es claro que la lengua de las oraciones era el latín. En el caso rioplatense tenemos el ejemplo de una oración para la apertura de nuevo semestre en el Colegio Máximo cordobés, ya convertido en Universidad en el miércoles de ceniza de 1759 por un profesor anónimo. ${ }^{20}$ Es de la fase del apogeo del colegio de Córdoba.

Infelizmente sabemos poco sobre los libros utilizados en las cofradías; los inventarios solo mencionan raramente qué títulos o documentos pertenecían al uso de cofradías a pesar de que era obligatorio registrarlos. ${ }^{21}$ En los inventarios de las reducciones no se prestó atención a ese material que a menudo era conservado en un arca y no era registrado en detalle. Ese descuido no es especial porque también otros manuscritos de devoción indígena se consideraban raramente tan preciosos que debieran ser mencionados. $^{22}$

Damos un ejemplo de la propagación de las cofradías. En 1620, el Padre Oñate escribe sobre Asunción: "Hay en este colegio 16 de la Compañía, 7 padres, de los cuales el uno lee Casos, y 4 hermanos estudiantes, uno de los cuales lee gramática, y los 3 oyen Casos, y 5 hermanos coadjutores tiene para ayudar a las almas. No solo los estudios de Casos de Conciencia y de Gramática que dos años antes se entablaron, favoreciéndoles mucho el Sr. Obispo, que era en extremo afecto a la Compañía, y una escuela de niños muy copiosa donde se les enseña la doctrina con grande cuidado, sino también una famosa congregación o cofradía de indios y la Congregación de estudiantes"23.

\footnotetext{
${ }^{19}$ Leonhardt, 1931, § VIII.

20

Publicado en latín y con traducción en: Fraschini, 2009, su titulo es: Oración de ostenta, Año 1759, traducción de Eduardo Fraschini, 1.c., pp. 75-101. El original está en la Biblioteca del Escorial (código manuscrito del Escorial J-III-9), con otra oración en latín con el mismo título y otros nueve en español, una con cierre en latín, ver l.c. p. 22.

Ver por ejemplo en el Inventario de Montevideo tomo 425 de la colección Jesuitica del Archivo de Santiago de Chile, en línea: http://jesuitas.archivonacional.cl/. Menciona en el colégio de Montevideo "un libro grande en Pergamino de la congregacion de la Buena muerte", f. 231v. Muchos inventarios contienen también una nota acerca de que ciertos materiales de poco valor no están incluidos en las listas y se encuentran en arcas.

${ }^{22}$ Ver la lista de los manuscritos en guaraní (la mayoría hoy perdidos) en el colegio de Asunción en facsímil del manuscrito original en el Anejo del Catalogo de la Biblioteca Jesuítica de Asunción publicado en: Gorzalczany / Gaona, 2006, pp. 454-456. Original en: AGN, Buenos Aires. Sala IX, 22-8-4, N 1, Legajo 2.

23

En Hernández, 1913, II, pp. 514-614 se encuentra de Cardiel, Breve relación de las Misiones del Paraguay. Ver también Kostianovsky, 2011.
}

94 Franz Obermeier. Los géneros didácticos en la literatura jesuítica rioplatense.... 80-103. 
Suponemos que estudios ulteriores pueden mostrar que los múltiples manuscritos devocionales de las reducciones en el siglo XVIII e impresos como los libros del Yapuguay eran también hechos para el uso en esas cofradías. Es muy factible, sin poder probarse en el estado actual de la investigación, que otro texto como el Joseph Insaurralde (1633-1730), Ara poru [Buen uso del tiempo], Madrid 1759/1760, publicado 30 años después de la muerte de su autor, jesuita y superior del Paraguay (1726-1730), es uno de eses textos típicos para un uso multiforme, pero también para devoción particular y en las cofradías. Es de notar que el de Insaurralde es el único libro publicado en guaraní por los jesuitas después de los de la primera imprenta en las Reducciones (dejando al lado los pocos textos de la segunda imprenta jesuítica de Córdoba en el Paraguay de 1766). Muestra que era un texto que parecía útil, y tan valioso que todavía se lo publicó decenios después de la muerte de su autor. Investigaciones futuras sobre ese texto (del cual no hay un análisis o traducciones de párrafos) tal vez pueden resaltar esos aspectos. ${ }^{24}$ En ese contexto tenemos que mencionar también textos históricos como varias traducciones de la Conquista espiritual en guaraní, ciertamente también leídos en las cofradías. ${ }^{25}$

Tenemos que nombrar para completar la presentación de la literatura didáctica jesuítica brevemente, también otro aspecto poco investigado: el de la didáctica linguiística.

\section{Didáctica lingüística}

Tomamos como ejemplo de análisis para entender esa funcionalidad de documentos un paratexto, en las llamadas Phrases selectas de $1687^{26}$, un manuscrito que se autodefine como una actualización del Tesoro de Montoya (Chamorro, 2014). ${ }^{27}$ Contiene paratextos anónimos muy ricos en información. Las Phrases selectas contienen como paratexto una dedicatoria y un prefacio al lector, todos sin firma de autor o editor. La dedicatoria es "A los fervorosos y apostolicos padres misioneros de la Compañia de Iesus en las Provincias de Paraná y Uruguay Mis padres amatissimos". El "narrador" de ese texto es idéntico con el autor y forma parte del grupo de los jesuitas porque llama a los otros sus colegas y amigos espirituales. Se dirige ficticiamente a otro personaje, tal vez un jesuita de puesto más alto en la jerarquía de la Orden, aunque no se clarifica quién era o qué función tenía. No es necesario saber o reconstruir quién era, se trata más de un acto de habla estilizado en tal tipo de paratexto y cuenta más la intención de insertarse en una institución y responder a pedidos de los provinciales o de otros. Aparece de la parte del autor el topos de la modestia de no escribir para sus propios fines o para el reconocimiento de otros, sino por el éxito de la causa misionera común y ha pedido de sus correligiosos. Además de ser un motivo tradicional, puede ser también que el texto sea el trabajo de varias generaciones de jesuitas. Vemos semejante aspecto didáctico también en otras Artes abreviadas de gramática indígena. Tenemos un ejemplo de ori-

\footnotetext{
${ }^{24}$ Ver Insaurralde, 1759, II. Sobre él: Caraman, 2001, pp. 2038-2039. 25

${ }^{25}$ Edición de un ms. Berlin/Cracovia en preparación por Manfred Ringmacher.

26 NN: "Phrases selectas y modos de hablar escogidos y usados en la Lengua Guaraní. Sacadas del Th soro escondido que compuso el venerable padre Antonio Ruiz de nuestra compañía de Jesús para consuelo y alivio de los fervorosos misioneros principiantes en la dicha lengua". Museo Mitre de Buenos Aires, referencia 14/4/41.

${ }^{27}$ Para la datación de ese manuscrito y de otros documentos ver también Cerno / Obermeier 2013.
}

95 Franz Obermeier. Los géneros didácticos en la literatura jesuítica rioplatense.... 80-103. 
gen rioplatense en un manuscrito de 1718. Formaba parte de la colección del Emperador Pedro II (hoy no se sabe su paradero) escrito por un anónimo en 1718 y editado por el profesor de lengua de ese monarca, el alemán Seybold en 1890. Consiste de 80 páginas y se ve claramente el fin didáctico de tal texto breve en comparación con el Arte de Montoya para aprendizaje básico de la lengua guaraní. Una comparación de los temas de esas gramáticas abreviadas con las grandes gramáticas extensas puede también ayudar a ver los temas que los jesuitas consideraban más importantes para dominar la lengua y atribuir a ella una cierta elegancia estilística, que han tenido como característica para el guaraní (Ruiz de Montoya, 1996).

\section{Conclusión}

Hemos visto que el aspecto didáctico de la literatura rioplatense todavía está poco investigado pero se encuentra en diferentes características en el centro de varios géneros de la literatura rioplatense colonial. Focalizar ese aspecto como uno de los elementos dominantes de una gran variedad de textos puede ayudar a determinar el aspecto intencional de ciertos textos, sean impresos o manuscritos y también establecer más claramente el vínculo de ciertos géneros con el público al cual estaba destinado. El público no son solo los indígenas mismos, sobre todo en las cofradías, sino también los jesuitas que quieren mejorar su uso pragmático del guaraní, para utilizarlo en la educación religiosa.

\section{Referencias documentales}

Manuscrito Gülich

N.N. Abschrift / eines / Im Privatbesitz des Herrn von Gülich befindlichen / Handschriftlichen/ Guaraní = Fragmentes / Im Auftrage von / Julius Platzmann / für Herrn Dr. Karl Henning / angefertigt durch / Emanuel Forchhammer / Leipzig, im März 1878

Philadelphia, Penn Library, Museum Library hoy Universidad Sección de libros raros.

En línea:

http://dla.library.upenn.edu/dla/medren/pageturn.html?id=MEDREN_4226236\&current page $=3$.

Otra copia más extensa en Luján, Museo Udaondo, ver Adoue/Oratin/Boidin (2015).

Inventario de Montevideo tomo 425 de la colección Jesuitica del Archivo de Santiago de Chile, en línea: http://jesuitas.archivonacional.cl/.

NN: "Phrases selectas y modos de hablar escogidos y usados en la Lengua Guaraní. Sacadas del Thesoro escondido que compuso el venerable padre Antonio Ruiz de nuestra compañía de Jesús para consuelo y alivio de los fervorosos misioneros principiantes en la dicha lengua". Museo Mitre de Buenos Aires, referencia 14/4/41

\section{Referencias Bibliográficas}

96 Franz Obermeier. Los géneros didácticos en la literatura jesuítica rioplatense.... 80-103. 
Adoue, C. /Orantin, M. / Boidin, C. (2015). "Diálogos en guaraní, un manuscrit inédit des réductions jésuites du Paraguay (XVIII ${ }^{\mathrm{e}}$ siècle)". Nuevo mundo/Mundos nuevos, http://nuevomundo.revues.org/.

Affani, F. M. (1999). "Participación indígena en la conformación de patrones religiosos y artísticos en las misiones jesuíticas de guaraníes. Estudio estadístico de la Iconografía en la escultura". Jesuitas 400 años en Córdoba, Congreso Córdoba 1999, tomo I, 25-42. Está incluido en una tesis del mismo título (Tesis de Doctorado, Universidad de Buenos Aires. Facultad de Filosofía y Letras. Doctor en Filosofía y Letras, Carrera de Ciencias Antropológicas, 2008, http://repositorio.filo.uba.ar/handle/filodigital/1288

Aguerre, N. (2015). La performance como comunicación estratégica en las ceremonias anuales del espacio jesuítico-guaraní. Tesis Universidad Nacional de La Plata (UNLP). http://sedici.unlp.edu.ar/handle/10915/45448.

Anchieta SI, J. (1977). Teatro de Anchieta. Originais acompanhados de trad. versificada, introd. e notas [por] Armando Cardoso, S.I. Obras completas Joseph de Anchieta. Vol.3. São Paulo: Loyola.

Angelis, P. de (1853). Colección de obras impresas y manuscritas que tratan principalmente del Río de la Plata, sin lugar. El texto de esa bibliografia está disponible en línea sin el Apéndice: http://www.cervantesvirtual.com. Para el Apéndice ver Obermeier 2017a.

Avellaneda, M. (2003). El Arcángel San Miguel y sus representaciones en las reducciones jesuíticas del Paraguay. Suplemento Antropologico, XXXVIII (2), pág.131175. http://www.academia.edu/

Batllori, M. (1990). "II dialogo in Spagna fra Medioevo e Rinascimento". En: Davide Bigalli / Guido Canziani (ed.), Il dialogo filosofico nel '500 europeo. Atti del Convegno Internationale di Studi, Milano, 28 - 30 maggio 1987, Milano: Angeli, pp.113-122.

Becker, M. (2003). Familiar dialogues in Englyssh and Frenche. Sprachliche Interaktion und ihre Vermittlung in der frühen Neuzeit, Trier: Wiss. Verl. Trier.

Bellarmino, Roberto (1597). Dottrina Cristiana Breve composta per ordine di [...] Papa Clemente VIII dal R.P. Roberto Bellarmino Sacerdote della Compagnia di Gesù. Venezia: Ciotti.

Bellarmino, Roberto (1598). Dichiarazione Più Copiosa Della Dottrina Cristiana [...], Roma: Mascardi.

Borucki, A. (2015). From Shipmates to Soldiers. Emerging Black Identities in the Rio de la Plata: University of New Mexico Press 2015 trad. española como: De compañeros de barco a camaradas de armas, Identidades negras en el Río de la Plata, 1760-1860, Buenos Aires: Prometeo 2017.

Briesemeister, D. (2004). "Humanistische Dialoge in Spanien im Übergang zur Frühen Neuzeit". En: Bodo Guthmüller / Wolfgang G.Müller (eds.), Dialog und Gesprächskultur in der Renaissance. Wiesbaden: Harrassowitz, pp.183-202.

Boethius, Anicius Manlius Severinus (1981). Consolatio philosophiae Boethius. Eingel, ausgew. und erläutert von Franz Xaver Herrmann. 2 tomos. Aschendorffs Sammlung lateinischer und griechischer Klassiker Münster: Aschendorff. 
Canisius SJ, Petrus (1555). Summa doctrinae christianae. Per Quaestiones tradita, et in vsum christianae pueritiae nunc primum edita, sine loco sine anno. Wien [Vienna]: Zimmermann.

(1556). Lectiones et precationes ecclesiastiae. Opus novum et frugiferum plane, in usum scholarum catholicarum, omniumque pietatis verae studiosorum. Ingolstadii: [Ingolstadt]: Weißenhorn.

(1558). SVMMA DOCTRINAE CHRISTIANAE. In vsum Christianae pueritiae per Quaestiones recens conscripta, et nunc denuò edita. Iussu \& authoritate Sacratissimae Rom. Hung. Bohem. \&c. Regiae Maiest. Archiducis Austriae, \&c. Vienna: Zimmermann.

Caraman, P. (2001). “Insaurralde”. En: Charles E.O.Neill / Joaquin María Dominguez (eds.), Diccionario histórico de la Compañía de Jesús. Madrid Univ. Comillas/Rom: Institutum Historicum, III, pp. 2038-2039.

Cardim, F. (1997). Tratados da terra e gente do Brasil, transcrição do texto, introdução e notas por Ana Maria de Azevedo, Lisboa: Comissão Nacional para as Comemorações dos Descobrimentos Portugueses.

Castellio, S. (1542-1545). Dialogorum sacrorum libri quatuor, Genf (Liber primus 1542, liber secundus et tertius 1543), como Dialogi de sacris literis excerpti, al linguam, mores que puerilis aetatis formandos non inutiles, Basilea: Zimmermann.

Castiglione, B. (1528) (escrito entre 1513 y 1524, publicado en forma definitiva en 1528). Libro Del Cortegiano. Venetia: Aldo Manutius.

Caxton, W. (1483). Dialogues in French and English [título moderno, el original no tiene frontispicio], Westminster.

Cerno, L. / Obermeier, F. (2013). "Nuevos aportes de la lingüística para la investigación de documentos jesuíticos de los siglos XVII y XVIII”. Folia histórica del Nordeste. Resistencia (Chaco), 21 pp. 33-56.

Chamorro, G. (2014). "PHRASES SELECTAS, Un diccionario manuscrito castellanoguaraní anónimo”. Corpus Vol. 4, No. 2.2014: Julio/Diciembre. En línea: http://corpusarchivos.revues.org/.

Cirio, N. P. (2000). “Antecedentes históricos del culto a San Baltazar en la Argentina. La cofradía de San Baltazar y Ánimas (1772-1856). " Latin American Music Review, 21. (2), pp.190-214.

Cruz, E. N. (2002). “Autoridades socio-religiosas en el antiguo régimen. Los mayordomos de cofradías en Jujuy a fines de la colonia". Cuadernos del Sur, 31, pp. 3556.

(2007). "Una cofradía urbana de indios a fines de la colonia: San Pedro de Naturales (Jujuy - Río de la Plata)”. Revista Andina, 44, pp. 227-248.

Dedekind, F. (1549) Grobianus. Francofurti: Egenolph.

Della Casa, G. (1558). Trattato Di Meser Giovanni della casa, nel quale sotto la persona d'un uecchio idiota ammaestrante un suo giouanetto si ragiona de modi, che si debbono ò tenere, ò schifare nella comune conuersatione, cognominato Galatheo. Rime, et prose di M. Giovanni della Casa. Impresse in Vinegia, per Nicolo

98 Franz Obermeier. Los géneros didácticos en la literatura jesuítica rioplatense.... 80-103. 
Bevilacqua, nel mese d'ottobre, 1558, pág. 82-170. Edición suelta: Milano: Antonius 1558 .

Fernandez Brandão, A. (1997) Diálogos das grandezas do Brasil. Organização e introd. José Antônio Gonsalves de Mello. Pref. de Leonardo Dantas Silva.3. ed. integral, s gundo apógrafo de Leiden. Recife: Fundação Joaquim Nabuco, Ed. Massangana

Fischer, R. (1989). Pater Martin Schmid. 1694 - 1772. Seine Briefe und sein Wirken. Zug: Kalt-Zehnder.

Fogelman, P. (2000). "Una cofradía mariana urbana y otra rural en Buenos Aires a fines del periodo colonial.” Andes, Antropología e Historia, Salta, pp.179-207.

(2006). "El culto mariano y las representaciones de lo femenino. Recorrido historiográfico y nuevas perspectivas de análisis.” Aljaba (Luján), pp.175-188, http://www.scielo.org.ar/.

Foltys, S. (1992). "Colloque de l'entree ou arrivee en la terre du Bresil entre les gens du pays nommez Tououpinambaoults, \& Toupinenkins en langage sauvage $\&$ françois". Neue Romania, 13, pp.17-103.

Fraschini, E. A. et al. (ed.), (2009). Literatura neolatina en el Río de la Plata. Villa Marıa: Eduvim.

Gilas, O.A. /Morales A.A./Martínez, R. A. (eds.), (2014). Devoción, paisanaje e identidad. Las cofradías y congregaciones de naturales en España y en América (siglos XVI-XIX), Bilbao: Universidad del País Vasco / Euskal Herriko Uniberstsitatea.

Gómez, J. (1988). El diálogo en el Renacimiento español. Madrid: Cátedra, 1988. Con un "Catálogo bibliográfico": pp. 217-230.

Gondra, Manuel (1990) “Auto de Adán”. Rela. pp.172-175.

González, N. N. (1994). “Orden, delito y castigo en la provincia misional jesuitica”. En: Luis Rodolfo González Risoto (ed.), Las Misiones Jesuítico-Guaraníes y el Desarrollo Regional Platense (congreso 5: 1994: Montevideo), Montevideo: Graphis, 1994, pp. 367-376.

Gorzalczany, M. A. / Gaona, A. O. (2006). La biblioteca jesuítica de Asunción, Buenos Aires: Edición de los autores.

Hartmann, C.C. de (2007). Lateinische Dialoge 1200-1400. Literaturhistorische Studie und Repertorium, Leiden: Brill.

Hempfer K. W. (ed.) (2004). Poetik des Dialogs. Aktuelle Theorie und rinascimentales Selbstverständnis, Stuttgart: Steiner.

Hernández, P. (1913). Organización social de las doctrinas guaraníes de la Compañía de Jesús, 2 tomos, Barcelona: Gili.

Hüllen, W. (2006). English dictionaries 800 - 1700. The topical tradition, Oxford: Clarendon Press. 
Insaurralde SI, J. (1758/1769). Ara poru agu iyey haba [ó Buen uso del tiempo] Pay Joseph Insaurralde... 1759, Madrid: J. Ibarra $15 \mathrm{~cm}, 2$. tomos, tomo 1, 1759 [xxii], 464 p. Tomo 2, 1760, 10.

Kilian, J. (2002). Lehrgespräch und Sprachgeschichte. Untersuchungen zur historischen Dialogforschung, (Germanistische Linguistik, 233), Tübingen: Niemeyer,

(2005). Historische Dialogforschung. Eine Einführung, (Germanistische Arbeitshefte 41), Tübingen: Niemeyer.

Kostianovsky, O. M. de. (2011). La instrucción pública en la época colonial. Escuela

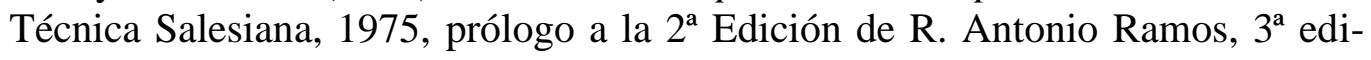
ción aumentada y corregida, Universidad Católica "Nuestra Señora de la Asunción", Biblioteca de Estudios Paraguayos, 92. En: http://www.portalguarani.com/2016_olinda_massare_de_kostianovsky_/15039_1 a_instruccion_publica_en_la_epoca_colonial_olinda_massare_de_kostianovsky .html.

Leite SI, S. (2004) [1938]. História da companhia de Jesus no Brasil. 1 ed. Fac-Símile [de la edición Lisboa 1938], Belo Horizonte; Rio de Janeiro: Ed. Itatiaia, 10 tomos.

Leonhardt, K. (1931) S.I., Bosquejo histórico de las congregaciones marianas en la antigua provincia de Paraguay, Chile y Tucumán de la Compañía de Jésus. Buenos Aires [s.n.].

Léry, J. de (1980) [1578]. Histoire d'un voyage faict en la terre du Brésil. Genève: Chuppin]. Nueva ediciòn: Genève: Chuppin 1580, ed. facsimilar de esa ed. por Jean Claude Morisot et Louis Necker, Genève: Droz.

Luca, M. C. De. (2010). "Las cofradías de indios en el territorio de Charcas (siglo XVIII). Balance historiográfico y nuevas propuesta de análisis". Cambios y Permanencias, Bucaramanga, No 1. Diciembre, pp. 94-117. En: http://cambiosypermanencias.com.

Magalhães de Gândavo, P. (1576). História da Província Santa Cruz a que vulgarmente chamamos Brasil. Lisboa.

Melgarejo, A. O. (2014). Contribución a la medicina natural. Pohã Ñana, un Manuscrito inédito en Guaraní (Paraguay, S. XVIII), Corpus, Vol 4, (2). En: http://corpusarchivos.revues.org/

Monteiro Lobato, M. (1927). Aventuras de Hans Staden, São Paulo: Companhia Editora nacional.

Moos, P. von. (1993). "Die italienische "ars arengandi" des 13. Jahrhunderts als Schule der Kommunikation“. Horst Brunner / Norbert Richard Wolf (ed.), Wissensliteratur im Mittelalter und in der frühen Neuzeit. Wiesbaden: Reichert, pp. 67-90.

Muratori, L. A. (1743). Cristianesimo felice nelle missioni de' padri della Compagnia di Gesù nel Paraguai. Venezia: Giambatista Pasquali.

Nadal, G. (1593). S. I. Evangelicae historiae imagines. Anversa [Martin Nuyts]

Obermeier, F. (2006). Der argentinische Erstdruck, Nierembergs De la diferencia in Guarani im Kontext der Bilderzyklen in Lateinamerika im 18. Jahrhundert. Pu- 
blicación en línea. URN: urn:nbn:de:bsz:16-artdok-1548; http://archiv.ub.uniheidelberg.de/artdok/volltexte/2006/154/

(2011) "Wie und mit welchen Mitteln erforschte man südamerikanische Indianersprachen”. Wolfenbütteler Notizen zur Buchgeschichte, 35. (2), pp.167183. En: http://macau.uni-kiel.de/.

(2015) "Die Anfänge der argentinischen Ethnolinguistik im 19. Jahrhundert". Auskunft 24. (2), pp.217-257. En: http://macau.uni-kiel.de/.

(2016a). Brasilien „für die Jugend und das Volk“. Kinder- und Jugendliteratur aus und über Brasilien vom 18. Jahrhundert bis in die Mitte des 20. Jahrhunderts. Publicación en línea: http://macau.uni-kiel.de/receive/macau_publ_00001314.

(2016b). Der Beginn literarischer und linguistischer Beziehungen zwischen Argentinien und Deutschland im 19. Jahrhundert. Der Beitrag von Friedrich von Gülich, congreso de Hispanistas de Heidelberg 2015. Publicación en línea: 2016 en: http://macau.uni-kiel.de/

(2016c). "Die Inventare der Jesuitenreduktionen bei der Vertreibung des Ordens aus dem La-Plata-Raum im 18. Jahrhundert und ihre buch- und bibliotheksgeschichtliche Bedeutung". Wolfenbütteler Notizen zur Buchgeschichte 41, caderno 1/2; pp.77-106.

(ed.) (2017a). "El Apendice a la Colección de obras impresas y manuscritas [1853] de Pedro de Angelis, una reconstrucción de la parte etnolingüística de su colección.” IHS Vol. 5, Núm. 2 (2017): (Julio / Diciembre), pp. 3-27. En: https://revistas.unc.edu.ar/index.php/ihs/index.

(2017b). "Ein neu entdecktes Guarani-Manuskript zur Tradition der Materia médica misionera im 18". Jahrhundert. Auskunft 37.(1), pp. 111-139. En: http://macau.uni-kiel.de/receive/macau_publ_00001535.

Ortiz de Villegas, Diogo (1504) Cathecismo Pequeño da doctrina \& instruiçam que os xр̄āos ham de creer \& obrar pera conseguir a benauenturança eterna. Lisboa: Valentin Fernandez.

Pawling, P. C. (2004). De la Compositio Loci a la República de las letras. Predicación jesuita en el siglo XVII novohispano, Mexico: Universidad Iberoamericana.

Peña, G. A. (1994). "La integración del indio en la Iglesia cordobesa, siglos XVI y XVII". Investigaciones y Ensayos, 44, pp. 365-380.

Pla, J. (1967). “Teatro en el periodo colonial y teatro misionero”, IV Departamento [de] Cultura y Arte: su organización y desarrollo; y Cuatro siglos de teatro en el Paraguay 1544 - 1964. Centenario de la epopeya nacional 1864 - 1970, parte primera. Asunción: Municipalidad 1966 (2.a ed. 1967). En: http://www.portalgua$\underline{\text { rani.com }}$

Rela, W. (1990). Teatro jesuítico, 2. ed., Montevideo: Universidad Católica del Uruguay

Rosal, M. A. (2006). "Diversos aspectos atinentes a la situación de los afroporteños a principios del período post-revolucionario derivados del estudio de testamentos 
de morenos y pardos." Revista de Indias, 66. (237), pág. 393-424. http://www.redalyc.org/.

(2007). "Asociaciones afroamericanas. Algunas consideraciones sobre las cofradías religiosas de morenos y pardos en Hispanoamérica (siglos XVI-XIX)." Idéa viva, Buenos Aires, pp. 60-67.

Ruiz de Montoya, A. (1639). Conquista espiritual hecha por los religiosos de la Compañía de Jesús, en las provincias del Paraguay, Paraná, Vruguay, y Tape de Antonio Ruiz de Montoya. Madrid: Imprenta del Reyno.

(1640). Arte y bocabulario de la lengua guaraní. Madrid: Sánchez.

(1996). Apología en defensa de la doctrina cristiana que en la lengua guaraní tradujo el venerable padre fray Luis de Bolaños, 1661 primera edición como Antonio Ruiz de Montoya, Apología en defensa de la doctrina cristiana escrita en lengua guaraní, introd. y notas de Bartomeu Melià, Lima: CAAAP; CEPAG: ESPFL "Antonio Ruiz de Montoya".

Sales, L. R. (2011). O teatro jesuíta como instrumenta pedagógico na escola para índios dos séculos XVI $e$ XVII. Tese UFRRJ. En: http://www.ufrrj.br/posgrad/ppgeduc/paginas/docs_dissertacao/2011/AndreaSale s.pdf.

Sánchez, A. M. M. (2006). Cofradías y obras pías en Córdoba del Tucumán, Argentina: Advocatus Universidad Católica de Córdoba.

Scheidt, C. (1551). Von groben sitten und unhöflichen geberden. Erstmals in Latein beschriben durch Fridericum Dedekindum und jetzund verteutscht durch Casparum Scheidt. Worms: Hoffman.

Sepp, A. (1958). Algunas Advertencias Tocantes al Gobierno Temporal de los Pueblos (com tradução portuguesa) Antônio Sepp, S.J. Notas explicativas de Ignacio Schmitz, SI. Pesquisas 2, 1958, pp. 35-54. http://www.anchietano.unisinos.br/publicacoes/historia.htm.

Seybold, C. F. (1890) [1718]. Brevis Linguae Garani Grammatica Hispanicae a Paulo Restivo secundum libros Antonii Ruiz de Montoya et Simon Bandini. Stuttgardiae: Kohlhammer.

Soares de Sousa, G. (1938). Tratado descriptivo do Brasil em 1587. Ed. par Francisco Adolpho de Varnhagem 1851, São Paulo: Ed. Nacional, $3^{\text {a }}$ ed.1938.

Staden, H (2007 [1557]). Warhaftige Historia. Zwei Reisen nach Brasilien, (1548-1555) / Historia de duas viagens ao Brasil. Kritische Ausgabe / edição crítica: Franz Obermeier. Übertragung ins heutige Deutsch: Joachim Tiemann. Tradução ao português: Guiomar Carvalho Franco. Revisão: Augusto Rodrigues, (Fontes Americanae, 1), Kiel: Westensee-Verlag.

Stefano R. Di /Zanatta, L. (2009). Historia de la Iglesia argentina. Desde la Conquista hasta fines del siglo, 2. ed., Buenos Aires: Sudamericana.

Takeda, K. (2017). "The Jesuit-Guaraní Confraternity in the Spanish Missions of South America (1609-1767). A Global Religious Organization for the Colonial Integration of Amerindians." Confraternitas 28(1). 
Thun, H./ Cerno, L/ Obermeier, F. (eds.) (2015). Guarinihape tecocue - Lo que pasó en la guerra (1704-1705). Memoria anónima en guaraní del segundo desalojo de la Colonia del Santo Sacramento / Uruguay de los portugueses por los españoles, edición crítica en transliteración diplomática con traducción al castellano, introducción y notas por Harald Thun, Leonardo Cerno y Franz Obermeier. Kiel, Westensee-Verl. 2.ed. corrigida: Posadas: Flor del Desierto.

(2018). Ang tobeete acôy teco cò mombĭrı̆agui - Dejad ahora aquellas costumbres ancestrales. Manual anónimo en guaraní de la gestión de las Reducciones (inicio del siglo XVIII, Manuscrito Gülich), edición crítica con reproducción facsimilar del original, traducción al castellano, introducción y notas de Harald Thun, Leonardo Cerno, Franz Obermeier, con la ayuda de Angélica Otazú Melgarejo, Kiel: Westensee-Verl. En preparación.

Torres, M. M. J. (2006). As práticas discursivas da Companhia de Jesus e a emergência do "teatro jesuítico da missão" no Brasil do século XVI, Tese (Doutorado em História)-Universidade de Brasília. http://repositorio.unb.br/handle/10482/7629

Verdu, R. (1973). La retórica española de los siglos XVI y XVII. Madrid: Consejo superior de investigaciones.

Villaret, E. (1947). Les Congrégations mariales. Paris: Beau Chesne

Weeks, J. M. (2002). The library of Daniel Garrison Brinton. Philadelphia, Pa.: Univ. of Pennsylvania Museum of Archaeology and Anthropology 2002. En: http://www.library.upenn.edu/eresources/brinton.pdf.

Yapuguay, N. (1724). Explicacion de el catecismo en lengua guaraní por Nicolas Yapugai, con direccion del P. Paulo Restivo de la Compañía de Jesús. En el Pueblo de S. María La Mayor.

(1727). Sermones y Exemplos en lengva gvarani por Nicolas Yapuguay, con direction de vn religioso de la Compañia de Iesus. En el Pueblo de San Francisco Xavíer.

Yves d'Évreux, (2014). Voyage au nord du Brésil (1615), édition critique du texte complet établi par Franz Obermeier, Kiel: Westensee-Verlag 2012, en línea 2014: http://macau.uni-kiel.de/receive/macau_publ_00000654. 